\title{
Influence of formulated organic Plant tissue culture medium in the shoot regeneration study of Brassica juncea (1.) - Indian mustard
}

\author{
Suman Kashyap $\cdot$ Seema Tharannum $\cdot$ Taarini $\mathbf{R}$
}

Received: 18 March 2019 / Revised: 22 May 2019 / Accepted: 14 June 2019

(C) Korean Society for Plant Biotechnology

\begin{abstract}
Efficient protocol for plant shoot regeneration of Brassica juncea L. CZERN was established by using organic media components and growth stimulating factors of the vermicompost and coelomic fluids. Formulated organic plant tissue culture media (Vermicompost (30\%) extracts supplemented with $20 \mathrm{~mL} / \mathrm{L}$ coelomic fluid) have shown maximum shoot regeneration when compared with the Murashige and Skoog (MS) medium, which were supplemented with $1 \mathrm{mg} / \mathrm{L}$ 6-benzyladenine (BA) and $0.1 \mathrm{mg} / \mathrm{L}$ of Naphthaleneacetic acid (NAA). Cotyledon explants produced the highest shoot regeneration frequency from fourday-old germinated seedlings in comparison with non-germinated seedlings. The vermicompost extracts have proved to be the best organic plant growth media to induce shoots from cotyledons compared to the MS media. Statistically significant difference ( $\mathrm{P}=0.008)$ for the root length, shoot length ( $\mathrm{P}$ $=0.000350)$ and the leaves $(\mathrm{P}=0.375)$ of the mustard plantlets were analyzed successfully. The survival rate was $98 \%$ in the mustard cotyledons on the Vermicompost extract media and $63 \%$ on MS media respectively. The coelomic fluid also is much suitable to induce shoots from cotyledons at lower concentrations. It was also shown that the vermicompost extract, which comprised of humic acids along with coelomic fluid, affected shoot regeneration from the cotyledons. An efficient and organic shoot regeneration study was standardized and it can be applicable in the improvement of
\end{abstract}

\footnotetext{
S. Kashyap $(\bowtie)$

Department of Biotechnology, PES University, Bengaluru 560085, Karnataka, India

e-mail: sumkash925@gmail.com

S. Tharannum

Department of Biotechnology, PES University, Bengaluru

560085, Karnataka, India

Taarini $\mathrm{R}$

Department of Biotechnology, PES University, Bengaluru

560085, Karnataka, India
}

the economically important crops.

Keywords Mustard, Brassiccajuncea(L.)Czern, Vermicompost extract, Coelomic fluid, formulated organic media, Plant tissue culture media

\section{Introduction}

Brassica juncea L., named Indian mustard is commonly consumed as spice and oil in India. Besides edible uses, it is also been used in areas of pesticide and biodiesel development. The first cultivation of mustard was about 2500-1700 BCE during the Indus Valley Civilization. India is an important rape seed mustard producing country in the world, occupying largest area and has placed second in production. The name 'mustard' is derived from the Latin word "mustum", meaning must of old wine mixed with crushed seed. It is one of the most important spices in the world (Hemingway 1976). In India, rapeseed mustard is most important source of edible oil followed by groundnut. Successful plant tissue culture, micropropagation, regeneration and transformation of several species of Brassica are reported (Cao and Earle 2003; Eapen and George 1997; Mathews et al. 1990; Wahlroos et al. 2003). Establishment of efficient shoot regeneration protocol for large scale micropropagation and genetic manipulation of Indian mustard is a necessity as genotypic differences in shoot regeneration system was evident in B. juncea (Mathews et al. 1985; Chi et al. 1990).

Earthworm compost has proven to be nutritive (with NPK) organic fertilizer and powerful 'plant growth promoter' when compared with the commercially available synthetic fertilizers. It has positive effects on the properties of soil, improves its natural fertility and reduces the levels of contaminants. It proves to be beneficial to the soil microbes 
and tends to retain the nutrients required for plant growth for a longer period (Rajiv et al. 2009).

There is also substantial evidence that earthworms significantly boost the growth rates of microbes, including actinomycetes, algae, bacteria, fungi and yeasts populations in soil. These microbes releases 'plant growth regulators' (PGRs) such as 'ascorbic acids', 'auxins', 'cytokinins', 'gibberellins' and 'ethylene' in substantial quantities which stimulates plant growth (Frankenberger, et al. 1995). Vermicompost has shown results which consistently improves germination of seeds, enhances growth and development of seedlings and also increases productivity of plant more than synthetic fertilizers or growth inducers. Tomati et al.,1988 have investigated that vemicomposts contains plant growth stimulating hormones like 'cytokinins', 'gibberellins' and 'auxins' which were released by the earthworms.

In this communication, the effect of vermicompost extract and coelomic fluid in the form of organic growth media was standardized as a most reliable and effective shoot regeneration protocol. The present work resulted in effective standardization of the vermicompost $(30 \%)$ media with 20 $\mathrm{mL} / \mathrm{L}$ of Coelomic fluid on the growth of mustard seeds in comparison to MS Media along with NAA $(0.1 \mathrm{mg} / \mathrm{l})$.

\section{Materials and Methods}

\section{Culture Medium}

For proliferation of shoots, explants (cotyledons) were cultured on Murashige and Skoog (1962) medium containing 1 $\mathrm{mg} / \mathrm{L}$ BAP + $0.1 \mathrm{mg} / \mathrm{L}$ NAA, vitamins and $30 \mathrm{~g} / \mathrm{L}$ sucrose. Alternatively, organic formulated plant tissue culture media was standardized using coelomic fluid $(20 \mathrm{~mL} / \mathrm{L}$ filter sterilized using $0.45 \mu \mathrm{m})$ in vermicompost extract $(30 \%)$ medium to study the effects on regeneration of mustard shoots. Media is set to $\mathrm{pH}-5.7$ and solidified ( $9 \mathrm{~g} / \mathrm{L}$ agar) media were sterilized under standard autoclave conditions (temperature at $121^{\circ} \mathrm{C}$ and 15 psi pressure for 20 minutes).

Extraction of Coelomic fluid

Eudgrilus engeniae (50 grams), were subjected to chemical treatment (5\% ethanol and $2.5 \mathrm{mg} / \mathrm{ml}$ of EDTA) under refrigerated conditions for $2 \sim 3$ minutes. Chemically stressed earthworms released coelomic fluid which appeared thick straw coloured. After collecting the coelomic fluid, earthworms were washed well and left back in good condition into the Vermibin. Coelomic fluid obtained was used as supplement in organic vermicompost extract (30\%) media at $20 \mathrm{~mL} / \mathrm{L}$ concentration.

Explant preparation

The seed explants of Brassica juncea L - Indian mustard, were cleaned thoroughly. Healthy and stable seed explants were surface sterilized with $5 \% \mathrm{NaOCl}$ along with $1 \sim 2$ drops of tween 20 and $70 \%$ ethanol $(\mathrm{v} / \mathrm{v})$ subsequently. Seeds were then rinsed thrice thoroughly with sterilized water.

Mustard seeds were germinated in $(90 \times 15 \mathrm{~mm})$ Petri dish having filter paper (Whatman Grade 1) moistened with sterilized liquid MS media and Vermicompost extract media respectively for seed bioassay at $22^{\circ} \mathrm{C}$ in darkness (30 seeds per dish). After 72 hours, germinated seeds were inoculated into the agar based MS and formulated organic media bottles respectively.

Regeneration of mustard shoots techniques being performed in triplicates with 30 explants per experiment. Explants survived with shoot buds were assessed for shoot length, number of leaves and roots in both MS (control) and formulated organic media. Regenerated shoot buds in MS media were sub-cultured initially on $0.1 \mathrm{mg} / \mathrm{L}$ BAP supplemented MS media for shoot elongation. For rooting, elongated shoots were transferred into MS media containing $0.04 \mathrm{mg} / \mathrm{L}$ NAA. The procedure of shoot and root regeneration sub culturing separately was not required for plants in formulated organic media.

Hardening and transplantation

The rooted plantlets from MS and formulated organic media were thoroughly washed and transferred to cocopeat and vermicompost (1:1 ratio) in net pots. Later plantlets were acclimatized for 4 days at 16 hours light and 8 hours dark period in covered poly bags. Finally acclimatized plantlets were transferred to greenhouses.

\section{Statistical data analysis}

The number of explants which developed adventitious shoots and the number of shoots formed per explant were considered and its frequency were calculated. Each experiment was maintained in triplicates. All statistical analyses were peformed using Sigmastat 4.0 software. 


\section{Results and Discussion}

The optimal medium was standardized for cotelydonary explants of Brassica juncea (L.) CZERN, in plant tissue culture studies. After $3 \sim 4$ days on MS (hormone free liquid media) treated plates, regeneration of green shoot buds occurred whereas budding process started on second day on vermicompost extract treated plates. Germination ability of mustard seeds was recorded after $4^{\text {th }}$ day as $95 \%$ in MS whereas $99 \%$ in vermicompost extract and coelomic fluid treated plates. Germinated seeds were transferred onto solidified MS media supplemented with $1 \mathrm{mg} / \mathrm{L}$ BAP $+0.1 \mathrm{mg} / \mathrm{L}$ NAA (Fig. 1) and formulated organic media composed of vermicompost (30\%) extract supplemented with $20 \mathrm{~mL} / \mathrm{L}$ coelomic fluid (Fig. 2) respectively. Shoot regeneration was markedly increased by the addition of coelomic fluid to vermicompost extract media. Maximum number of shoot buds was seen in the fourth week of culture a greater number of shoots differentiated at the explant surface. Effect of vermicompost extract in combination with coelomic fluid on frequency of root development from cotyledon was presented in Figure 2.

Statistically the root length was calculated and the Normality Test (Shapiro-Wilk) being passed $(\mathrm{P}=0.284)$, Equal Variance Test (Brown-Forsythe) failed where $(\mathrm{P}<$ 0.050). Mann-Whitney U Statistic is 44 and $T$ is 149 whereas $\mathrm{n}$ is $14(\mathrm{P}=0.013)$. The difference in the median values between the Vermicompost extract media and the MS medium is greater than would be expected by chance; there is a statistically significant difference ( $\mathrm{P}=0.013)$.

Wilcoxon Signed Rank Test was used to compare the

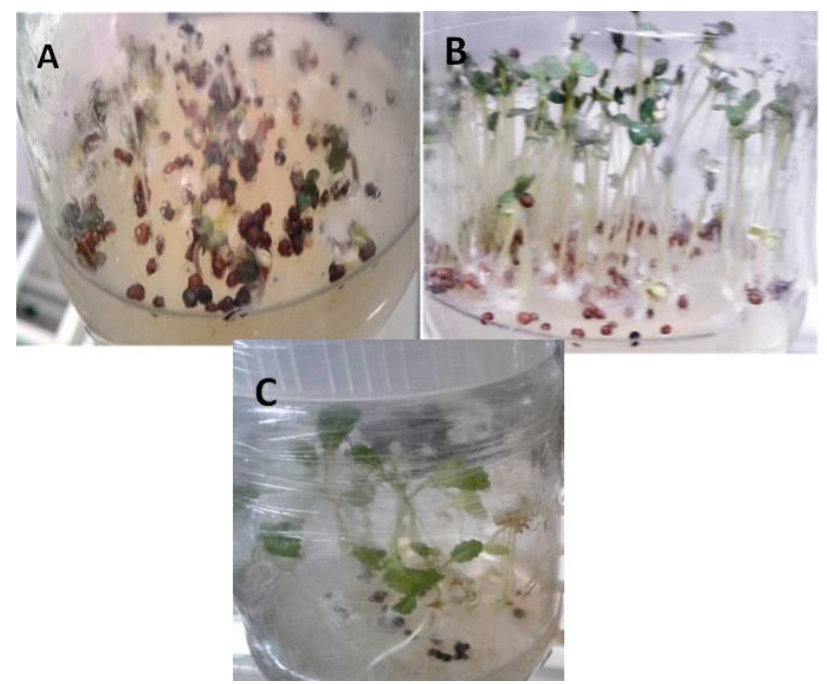

Fig. 1 Micropropagation of mustard on MS medium supplemented with $1 \mathrm{mg} / \mathrm{L} \mathrm{BAP}+0.1 \mathrm{mg} / \mathrm{L}$ NAA. A - One-week old culture; B - 20 days old culture; C and D 45 days old culture root length of mustard plants grown on MS and VC media and the Normality Test (Shapiro-Wilk) Failed $(\mathrm{P}<0.050)$. $\mathrm{W}$ is $36.000, \mathrm{~T}+$ is $36.000, \mathrm{~T}-$ is -0.000 . Z-Statistic (based on positive ranks) is $2.536 . \mathrm{P}$ (test.) is 0.014 and $\mathrm{P}$ (exact) is 0.008 . The change that occurred with the treatment is greater than would be expected by chance; there is a statistically significant difference $(\mathrm{P}=0.008)$ for the root length (Fig. 3) of mustard plantlets.

Wilcoxon Signed Rank Test was used for the shoot length of mustard plants grown on MS and VC media and the Normality Test (Shapiro-Wilk) Passed $(\mathrm{P}=0.252)$ (Fig. 3). Test execution ended by user request, Paired t-test begun. $t=-4.413$ with 13 degrees of freedom. 95 percent

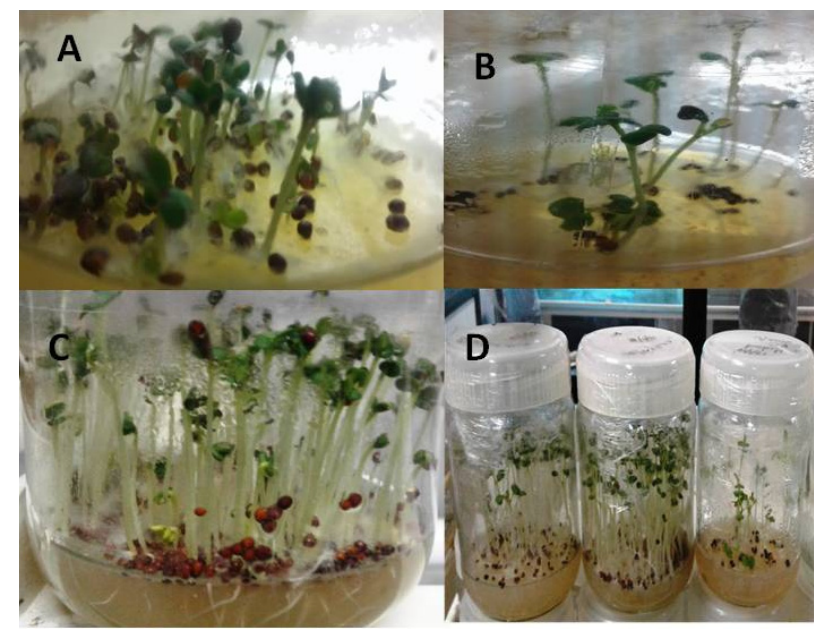

Fig. 2 Micropropagation of mustard on vermicompost medium supplemented with $20 \mathrm{ml} / \mathrm{L}$ coelomic fluid A - One-week old culture; B - 20 days old culture; C and D 45 days old culture

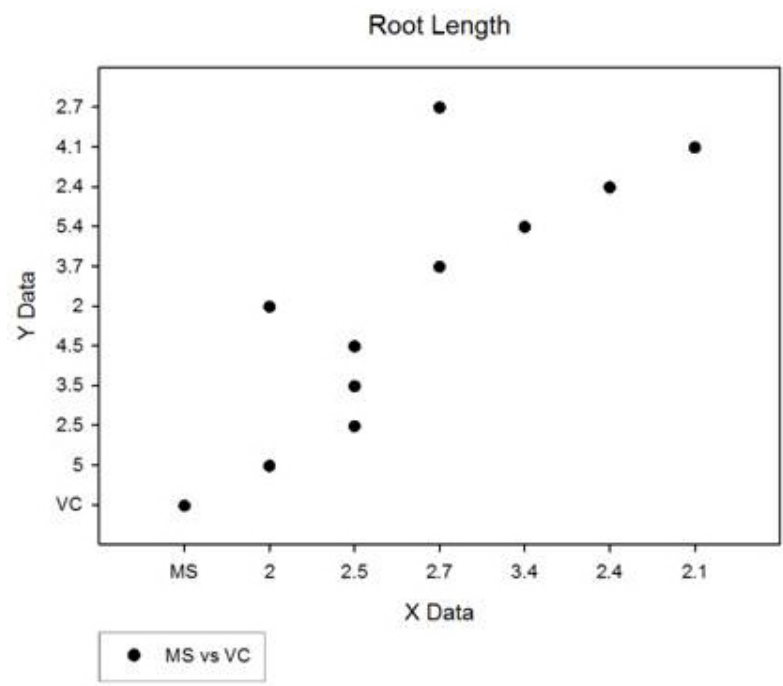

Fig. 3 Shows the results of wilcoxson signed rank test for the root length of plantlets grown in vitro on MS media and Vermicompost extract media 
Normal Probability Plot Shoot length MS vs VC

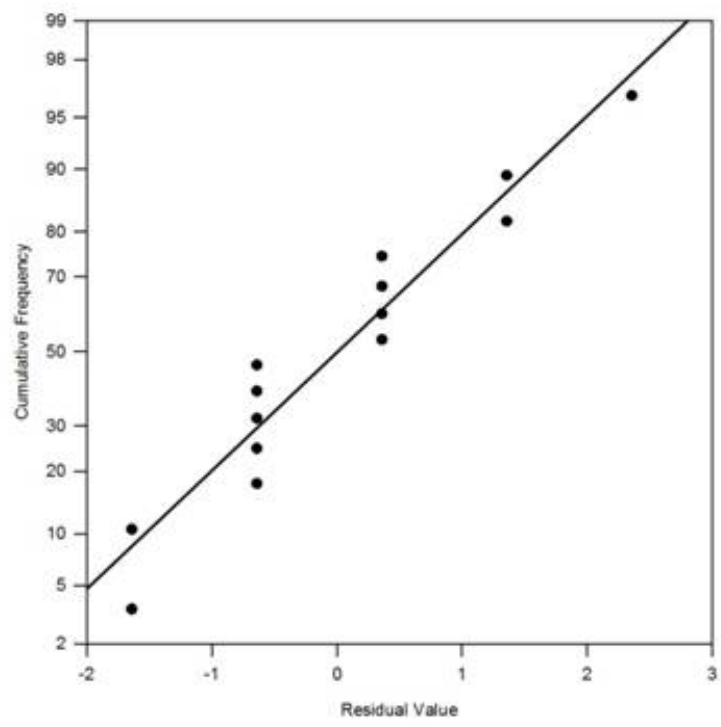

Fig. 4 Shows the results of wilcoxson signed rank test for the shoot length of plantlets grown in vitro on MS media and Vermicompost extract media

two-tailed confidence interval for difference of means: -2.022 to -0.693 . Two-tailed P-value is 0.000701 . The change that occurred with the treatment is greater than would be expected by chance; there is a statistically significant change ( $\mathrm{P}=<0.001$ ). One-tailed $\mathrm{P}$-value is 0.000350 (Fig. 4). The sample mean of treatment vermicompost extract exceeds the sample mean of treatment MS media by an amount that is greater than would be expected by chance, rejecting the hypothesis that the population mean of treatment MS is greater than or equal to the population mean of treatment Vermicompost extract media. $(\mathrm{P}=<0.001)$.

Power of performed two-tailed test with alpha is 0.050 : 0.982 .

Power of performed one-tailed test with alpha is 0.050 : 0.994.

Wilcoxon Signed Rank Test for number of leaves grown on MS and Vermicompost extract media was analyzed. Normality Test (Shapiro-Wilk) Failed ( $\mathrm{P}<0.050)$. W is 6.000, $\mathrm{T}+$ is 8.000 and $\mathrm{T}-$ is -2.000 . Z-Statistic (based on positive ranks) is 1.134 . $\mathrm{P}$ (test.) is 0.345 and $\mathrm{P}$ (exact) is 0.375 . The change that occurred with the treatment is not great enough to exclude the possibility that it is due to chance $(\mathrm{P}=0.375)$ (Fig. 5).

Most favorable shoot regeneration frequency was procured from formulated organic medium. This resulted in root (hairy) development. Shoot buds developed directly from the cut ends of cotyledons within week. The survival
Before \& After Line Plot

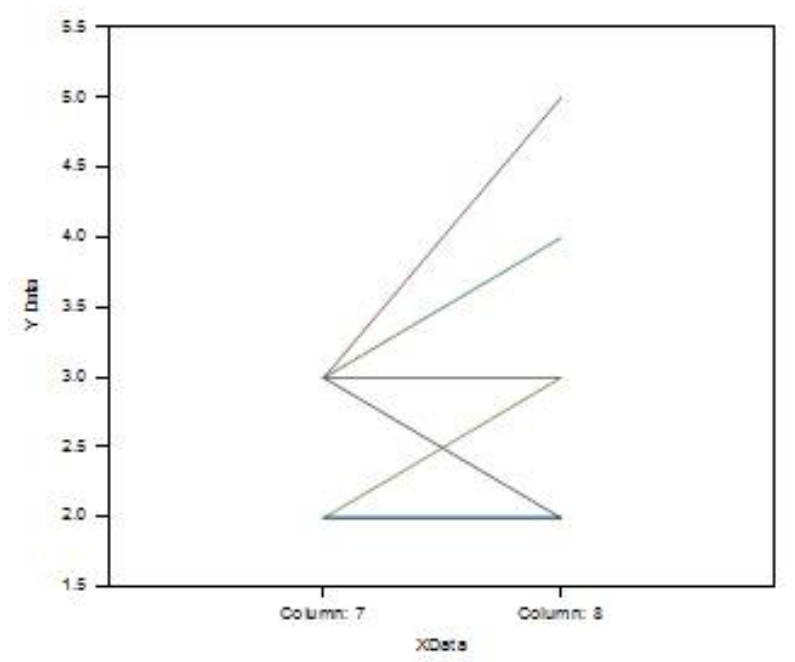

Fig. 5 Shows the results of wilcoxson signed rank test for the number of leaves seen on the plantlets grown in vitro on MS media and Vermicompost extract media

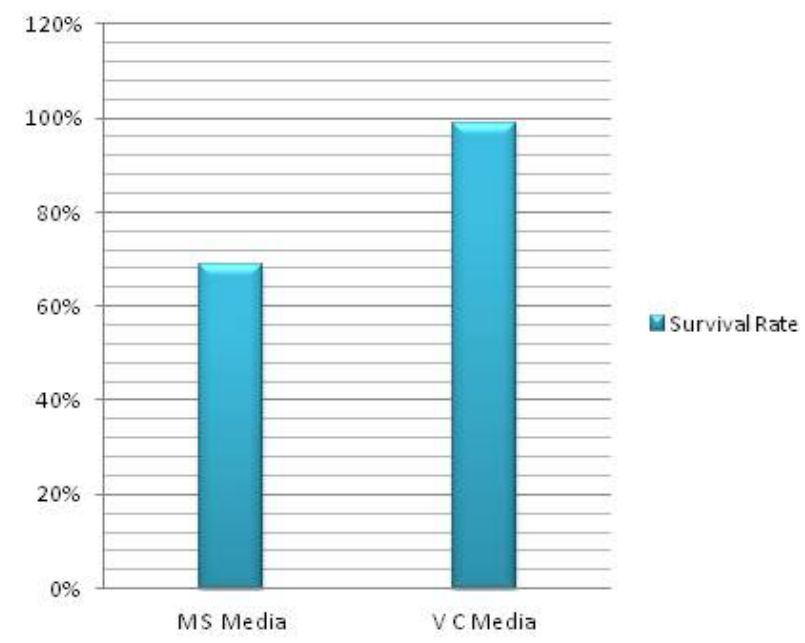

Fig. 6 Shows the percentage survival rate of the plantlets grown on MS and formulated organic medium respectively

rate was $98 \%$ in mustard cotyledons on Vermicompost extract media and $63 \%$ on MS media respectively (Fig. 6). Callus was not seen in cotyledon explants.

The results of present study shows that the seeds treated with the formulated organic media showed progressive enhancement in germination with respect to time. Successful micropropagation and transformation of B. juncea (L.) were investigated (Mathews et al. 1985; 1990). Czern and Coss are the important oilseed crop of India. In this study, it was an attempt to tissue culture mustard seeds systematically to compare the Vermicompost medium with MS medium. The results obtained indicated that it is 
possible to induce shoot regeneration directly on using economical formulated organic media on cotyledon segments of $B$. juncea L. TDZ was reported to be ideal for stable shoot proliferation of green ash (Kim et al. 1997). Shoot formation was poor with KT (6-furfurylaminopurine kinetin) in cotyledon. In the present study, higher concentrations of coelomic fluid reduce the rate of regeneration of shoots, without affecting its shoot morphology. Shoot regeneration frequency in cotyledons was high in most of the cases. The results obtained here are efficient, economical and reliable. Successful genetic transformation was reported in most of the Brassica species (Cao and Earle 2003; Metz et al. 1995; Wahlroos et al. 2003).

\section{Conclusion}

This protocol might be of help in genetic improvement using transgenic approach because mustard is targeted by severe viral infection. The plants had developed both roots and shoots without the requirements of separate rooting and shooting media as is done in traditional tissue culture methods. The humic and fulvic acids present in the vermicompost exhibit "hormone-like" activity which promote plant growth. This prevents the use of synthetic hormone supplements. This reduces the cost of the tissue culture process. Due to the antimicrobial activity of the coelomic fluid, contamination is prevented in case of MS Media is a significant probability. Thus one can say that with further research and standarization procedures, Vermicompost and Coelomic Fluid can be used as an alternative to the traditional synthetic media. Formulated organic media is advantageous due to its rich "plant-growth promoting "properties and convenience.

\section{Acknowledgements}

Thanks to The Management and The Chairperson, Department of Biotechnology, PES University, Bengaluru for providing an opportunity to pursue the present research.

\section{References}

Cao J, Earle ED (2003) Transgene expression in broccoli (Brassica oleracea var. italica) clones progated in vitro leaf explants. Plant Cell Rep 21:789-796

Chi GL, Barfield DG, Sim GE, Pua EC (1990) Effect of silver nitrate and aminoethoxyvinylglycine on in vitro shoot and root organogenesis from seedling explants of recalcitrant Brassica genotypes. Plant Cell Rep 9:195-198

Eapen S, George L (1997) Plant regeneration from peduncle segments of oil seed Brassica species: influence of silver nitrate and silver thiosulfate. Plant Cell Tiss. Org. Cult 51: 229-232

Frankenberger WT, Arshad M (1995) Phytohormones in Soils: Microbial Production and Function. Marcel and Deckker Pub., New York, pp 503

Hemingway JS (1976) Mustard: Brassica spp. and Sinapis alba (Cruciferae). pp 56-9. (in) Evolution of Crop Plants. Simmonds (Ed.). Longmans, London.

Kim MS, Schumann CM, Klopfenstein NB (1997) Effects of thidiazuron and benzylaminopurine on axillary shoot proliferation of three green ash (Fraxinus pennsylvanica Marsh.) clones. Plant Cell Tiss. Org. Cult 48:45-52

Mathews VH, Bhatia CR, Mitra R, Krishna TG, Rao PS. (1985) Regeneration of shoots from Brassica juncea (Linn.) Czern and Coss cells transformed by Agrobacterium tumefaciens and expression of nopaline dehydrogenase genes. Plant Sci 39:49-54

Mathews VH, Bharathan N, Litz RZ, Rao PS, Bhatia CR (1990) Transgenic plants of mustard Brassica juncea $\mathrm{L}$. czern and coss. Plant Sci 72:245-252

Metz TD, Dixit R, Earle ED (1995) Agrobacterium tumefaciensmediated transformation of broccoli (Brassica oleracea var. italica) and cabbage (B. oleracea var. capitata). Plant Cell Rep 15:287-292

Murashige T, Skoog F (1962) A revised medium for rapid growth and bioassay with tobacoo tissue culture. Physiol. Plant. 15:473-495

Sinha K, Rajiv, Herat Sunil, Valani, Dalsukhbhai, Chauhan, Krunalkumar (2009) Earthworms Vermicompost: A Powerful Crop Nutrient over the Conventional Compost \& Protective Soil Conditioner against the Destructive Chemical Fertilizers for Food Safety and Security, American-Eurasian Journal of Agricultural \& Environmental Sciences, pp 1-55

Tomati U, Grappelli A, Galli E (1988) The hormone-like effect of earthworm casts on plant growth. Biol Fertil Soils 5:288-294

Wahlroos T, Susi P, Tylkina L, Malyshenko S, Zvereva S, Korpela T (2003) Agrobacterium- mediated transformation and stable expression of the green fluorescent protein in Brassic arapa. Plant Physiol Biochem 41:773-778 